\title{
Can’t We All Use An Angel?
}

Leonard Presby, (Email: PresbyL@wpunj.edu), William Paterson University

\begin{abstract}
Educational institutions are looking for ways to reach students in a better manner, in the face of increased competition, shifting demographics and tighter budgets. Offering online courses is one of the ways this problem has been approached. As the internet has become integral to our everyday lives, web-based educational course management systems have become more common and more sophisticated. Blackboard, Webct, and ANGEL are three popular ones. The focal point of them is to aid instructors develop important learning experiences and improve learning outcomes They help to promote communication among and between students, support curriculum, assessments and surveys, facilitate team learning and group effort and feedback. This paper will help instructors and instructional designers who are considering course management systems. Results of the study show how one system provides users with superior results.
\end{abstract}

\section{INTRODUCTION}

$\mathrm{n}$ the face of increased competition, shifting demographics and tighter budgets, educational institutions are
looking for ways to reach students in a better manner. Most Universities face the same challenges: resources are scarce and demands placed on the system continue to grow. Personnel and financial resources must be effectively utilized to achieve the best possible return on investment in terms of both time and dollars. Of parallel concern is, how does one stimulate a student's interest in learning? One of the ways this problem has been tackled is by offering online courses. More than $70 \%$ of the colleges are employing distance learning courses to some degree. A survey by the National Center for Educational Statistics revealed that in 2000-2001, 56 percent of twoand four-year degree-granting institutions offered some type of distance learning, and 90 percent of those institutions deliver at least some of their courses via the Internet (NCES, 2003). Major universities, including Stanford University, Duke University, Cornell University and Tulane University, have embraced the virtual learning experience, offering some of their curriculum online.The trend towards the use of the Internet in academia is clear with a number of courses using the Web for the delivery of course material. This incorporates the facility to access subject matter content and support at a time, place and pace that is suitable and convenient for the individual learner As the internet has become integral to our everyday lives, web-based educational course management systems have become more common and more sophisticated. Many instructors are indeed presently using course management systems. The focus of them is to aid instructors develop meaningful learning experiences and improve learning outcomes They help to promote interaction among and between students, support curriculum, assessments and surveys, facilitate team learning and collaboration and feedback. Flexible access to information and resources are key features of online educational technologies. Specifically we could use some structure that will integrate technology, provide tools that assist instructors, save time and produce more positive outcomes, enhance interactions and engage students.

The purpose of this paper is to help individual faculty members (and instructional designers) who are considering course management systems. Results of the study show how one system provides users with better results and how instructors are to make use of this technology.

\section{BACKGROUND}

There are numerous systems available (also known as course management systems), some popular ones being Blackboard, Webct, Moodle and ANGEL. Most have similar features. Articles have been written comparing the functionality of these different systems (Hall 2003; Van de Pol 2001). 
They all typically present a streamlined user interface, utilize breadcrumbs and a course map, include images in quiz questions and permit randomization, allow an equation editor available during tests, have a built-in HTML editor, easily add video/multimedia, import/export grades to/from Excel.

Course management systems can perform dozens and dozen of things. Until recently, faculty used cms principally to manage the more mundane tasks associated with teaching. Much use was given to content presentation tools within the CMS (Morgan 2003). However, most instructors, presently, are interested in performing, typically, the following 10 functions:

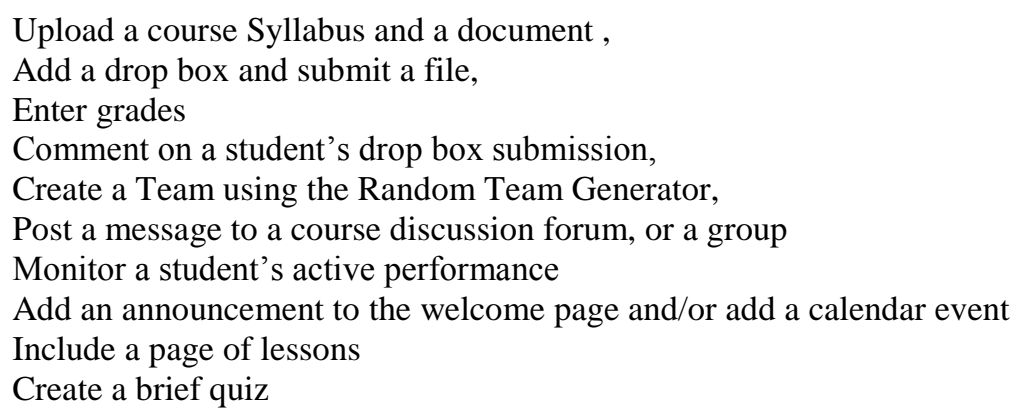

There is additional sophistication and flexibility in the advanced features. But these typically go unutilized by many. More than eighty percent of the four-year private and public universities that use course management systems have settled on a "single product standard" for course management, meaning they use one primary system (Green). My University has been using Blackboard for nearly a decade. Blackboard (Bb) is a powerful course management tool that combines the best of the web, email, and bulletin-board forums. Faculty can employ $\mathrm{Bb}$ as a medium to post content for and exchange information with students, and students can participate in meaningful learning collaborations. I have been using it in numerous courses, including MIS, Computer Applications, and POM. Utilizing this course management system has gone well. While most of us like status quo, there are others who ask, is there something superior? Upon request, I was asked to teach a similar course for a different University, this time employing ANGEL. I was intrigued since I researched that ANGEL obtained a high level of voluntary adoption Nearly eighty percent of faculty and students within the first year. Because ANGEL has a "normal" view for beginners and casual users that is simplified for basic use, even people somewhat uncomfortable with technology are using ANGEL. One account said "we switched to ANGEL because of cost and features. ANGEL evolved from research conducted in the Cyber-Lab on the campus of Indiana University Purdue University Indianapolis. The initial research system became Indiana University's On course. The system supports nearly 100,000 students on six Indiana University campuses. ANGEL customers include two of the largest universities in the United States, Penn State University and Michigan State University, large community college systems, small and large public and private postsecondary institutions. From an administrative point of view it had open and flex architecture, Customer-centric, ePortfolios, shared content repositories. It was also accessible to users with disabilities in compliance with Section 508 of Rehabilitation Act of 1973 and signed into law in 1998.

I found ANGEL provides instructors measurable time savings. It helps them develop meaningful learning experiences and improve learning outcomes. It provides timesaving, pedagogically effective tools. It was like having a teaching assistant. Moreover, there is added sophistication and flexibility in the advanced features.

Three of ANGEL's most powerful and unique areas are:

- $\quad$ Exception reporting and tracking.

- Content repositories and reuse.

- Dynamic personalized learning paths, (of which the first one would initially have the most use). 


\section{Exception Reporting and Tracking}

Intelligent and productivity agents help streamline the teaching and learning process. Exception Reporting and Tracking are examples of streamlined steps taken to achieve a specific, very common task. The agents enable one to monitor student progress and provide critical intervention and feedback, affecting positive learning outcomes. One example of exception reporting is ANGEL's WhoDunIt Agent. The agent's purpose is to quickly identify situations that are "out of bounds" and to communicate with the learner in an efficient manner. It allows the instructor to easily identify and e-mail users based on specific criteria such as "who has not completed their evaluation" or "who scored $90 \%$ or higher." It also allows the instructor to easily identify and email users on specific criteria such as "who has not completed their evaluation" or helps an instructor assess the need for critical intervention as well as positive feedback, based on results of the reporting tool. The What's New Agent displays all items (i.e., the exceptions) that the user may need to address. For example, you can use the What's New Agent to determine if any assignments have been submitted and not yet graded. Importantly, you can enter the grading form by simply clicking in the item in the What's New list. This tool, in essence, can serve as an automatically updated "to do" list.

\section{WhoDunIt - Completed Item}

Statistics for Business

The following people have completed case ch4.

\begin{tabular}{|r|l||l|}
\hline$\#$ & NAME & Username \\
\hline \hline 1. & Benchimol, Marge & benchimo \\
\hline 2. & Golubchik, Joseph & golubchi \\
\hline 3. & Green, Samuel & sygreen \\
\hline 4. & Green, Yair & ygreen 1 \\
\hline 5. & Guttmann, Joyce & jguttman \\
\hline
\end{tabular}

ANGEL's Learner Profile organizes all grading information in one display. Other information, or "views," about the instructor's interaction with a student that can be accessed includes a log of the student's activity on the system, all email correspondence, and message and chat participation. On any of these views, you can "drill in" for more detail by clicking on the item.

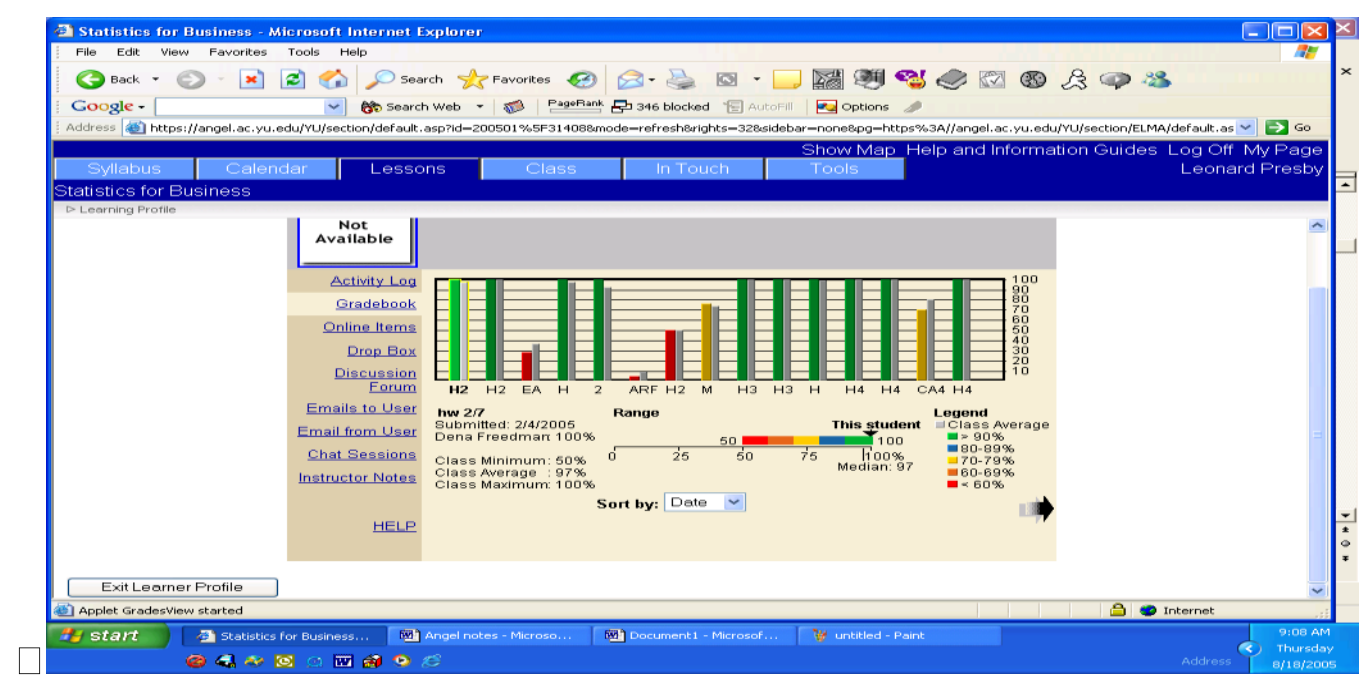


The Learner Profile organizes all the interaction points between the student and the instructor into a studentcentered view. The task is to "perform a quick, comprehensive review of students' performance and drill where needed to determine if the instructor should take action."

Other good examples of ANGEL's exception reporting, tracking, and task-oriented tools include: $\square$ determining who has not logged in for a specified period, drilling into individual student's participation on a threaded discussion board and being able to grade it, $\square$ changing the answer on a test and optionally having ANGEL re-grade previous submissions.

\section{Content Repositories and Reuse}

To encourage sharing, reuse, and repurposing of learning content, ANGEL offers repositories/resource libraries that can be organized by course, department, school and campus. These libraries are used to store useful ANGELlearning objects. All forms of ANGEL content, or objects, can be stored in the library including web pages, files, assessments, surveys, drop boxes, etc. to be reused by others with access to the library

\section{Learning Paths}

For high-enrollment courses or courses that you teach repeatedly over time, you may be interested in making individual student's experiences dynamic based on their performance, their learning style, or other learner-specific attributes. ANGEL supports this type of personalization through a unique feature called "Triggers and Actions." Triggers and Actions provide advanced capabilities to enable ANGEL to take an action on your behalf when a specified event occurs or a condition is met. For example, Unit 7 can be conditionally released to students when they achieve greater than $85 \%$ on the Unit 6 assessment. Triggers and Actions can also be used to provide encouragement, such as a congratulatory email when a student achieves greater than $95 \%$ on a test.

\section{Method - author's opinion, students opinion, other faculty}

Exploring ANGEL further to see why it is the preferred system, one chooses the Tool option.

\begin{tabular}{|c|}
\hline INSTRUCTOR TOOLS \\
\hline $\begin{array}{l}\text { Attendance Manager } \\
\text { Take attendance and review attendance information }\end{array}$ \\
\hline $\begin{array}{l}\text { Course Gradebook } \\
\text { Manage both on-line and off-line grades for this course }\end{array}$ \\
\hline $\begin{array}{l}\text { Learner Profile } \\
\quad \text { Learner-centric performance measures and statistics }\end{array}$ \\
\hline $\begin{array}{l}\text { Milestones } \\
\quad \text { Manage Course milestones and review user progress }\end{array}$ \\
\hline $\begin{array}{l}\text { Ungraded Items Agent } \\
\text { Lists all items with one or more ungraded submissions }\end{array}$ \\
\hline $\begin{array}{l}\text { User Preview Tool } \\
\text { Preview how the course looks to users based on their rights team } \\
\text { associations }\end{array}$ \\
\hline
\end{tabular}

The instructor has the ability to customize the attendance screen to allow only days that class is in session. Furthermore, he/she has the ability to classify the attendance as present, late, sick or some other description. 
ANGEL incorporates intelligent agents, such as, Learner Profile, that enable instructors to monitor student progress and provide critical and feedback affecting positive learning outcomes. As alluded to earlier, the Learner Profile organizes all interaction points between student and instructor into a student-centered view.

The Agent keeps instructors on top of student activity by automatically alerting them when students are not meeting performance expectations. It keeps a log of student's activity on the system, all email correspondence, message and chat participation.

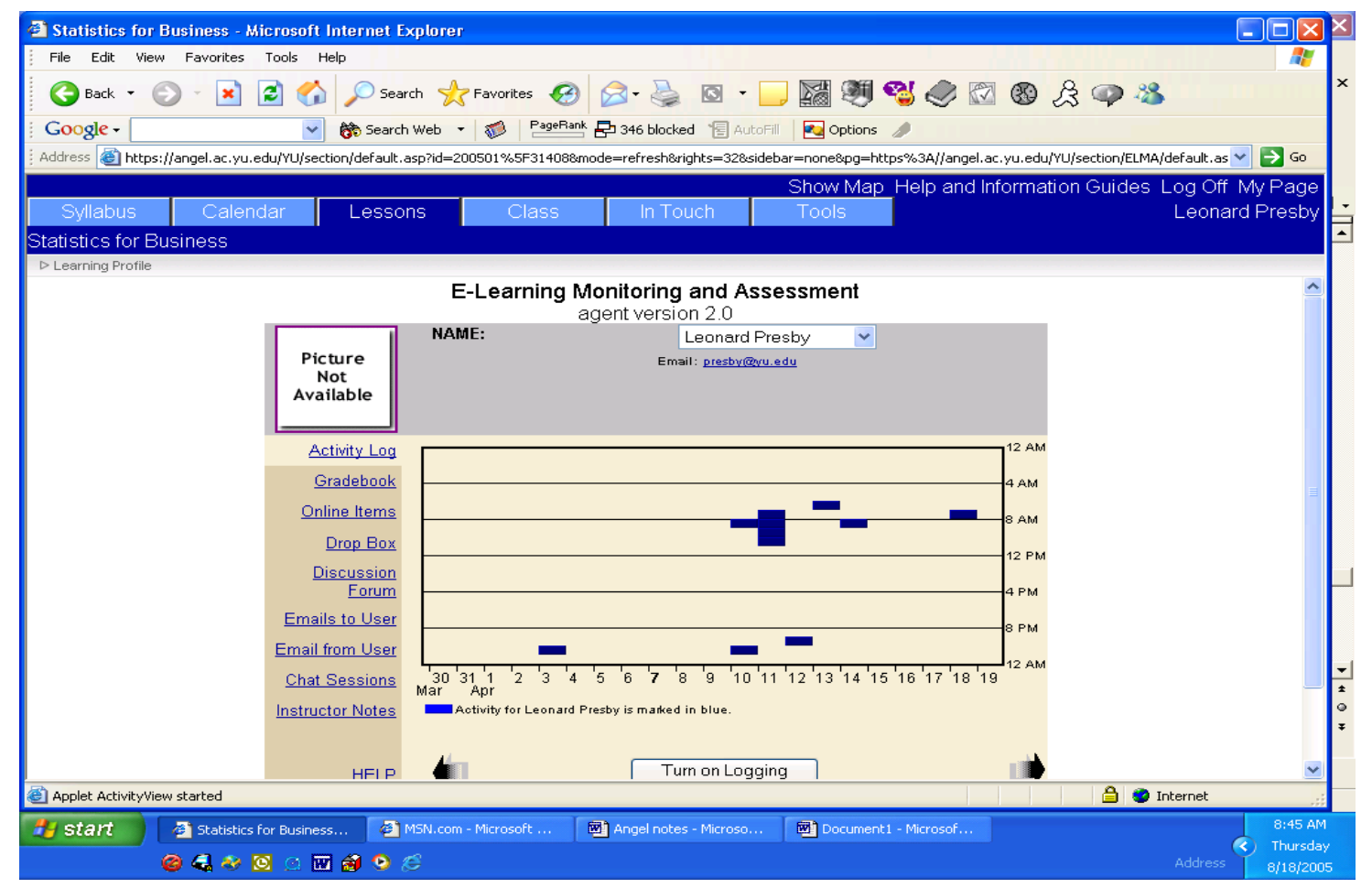

Instructors can include real-time video with slide or web presentations within the optional synchronous tools. Course developers can integrate streamed Real audio and video into a course. Students can create, share, categorize and annotate bookmarks in a personal folder. Students can bookmark any content material in a course. Students can create online clubs, interest, and study groups. Students can send email to their groups, use a shared chat space, calendar and announcements, and share material privately within the group. Students from different courses can interact in a system-wide chat rooms or discussion forums. Instructors can maintain private notes about each student in a secure area. Instructors can get a report that summarizes individual student performance on assignments. A flag can be set on individual course components to track the frequency with which students access those components. custom reports can be obtained. Instructors can share tracking information with students. Instructors can get a report displaying the date/time each student accessed a specific course assessment, assignment, or self-assessment. Instructors can view all student folders simultaneously. The system supports management of curriculum and competencies. Instructors can specify prerequisites and sequence of each course within the curriculum. Multiple paths can be specified through courses for different skill levels or job functions. ANGEL also allows unlimited discussion forums, allows the forums to be defined by type of post to stimulate effective discussion. In this schema, discussion forums become powerful teaching and learning tools that engage students in active learning. One can delete a course as well as show an earlier taught course. A grade tutorial is useful for the first time user and the ability to continue where one, which ANGEL indicates, has left off can save time. In Class, under User Profile, one is able to see other classes that the student is enrolled. 
One of numerous responses I observed is "I used Blackboard for 3 years before moving to ANGEL. ANGEL allows you to place drop boxes, discussion forums, quizzes, etc. right in the same area (folder) of your course content. In Bb, you had to leave the course content area to do any of this and then click back into the course and locate where you left off." Another wrote "Faculty and others using it here also indicate to me how much easier it is to use ANGEL. This includes enrolling students which we allow some users to do. Setting up teams is also less cumbersome; there were several steps in $\mathrm{Bb}$. I particularly like the navigation menu on the left side of the screen which assists users in locating what they want quickly." And, "From the System Admin point of view, there is less of a requirement to go to the admin menu, most everything is done in the course view. This also saves time and clicking. I find I don't need to have two windows open to do the work and then see what it looks like. I can't think of anything I miss about Blackboard."

One of the powerful features in Angel is Instructor Reports. One of them shows which students signed in for a particular day.

\section{Logged Activity Report}

Statistics for Business

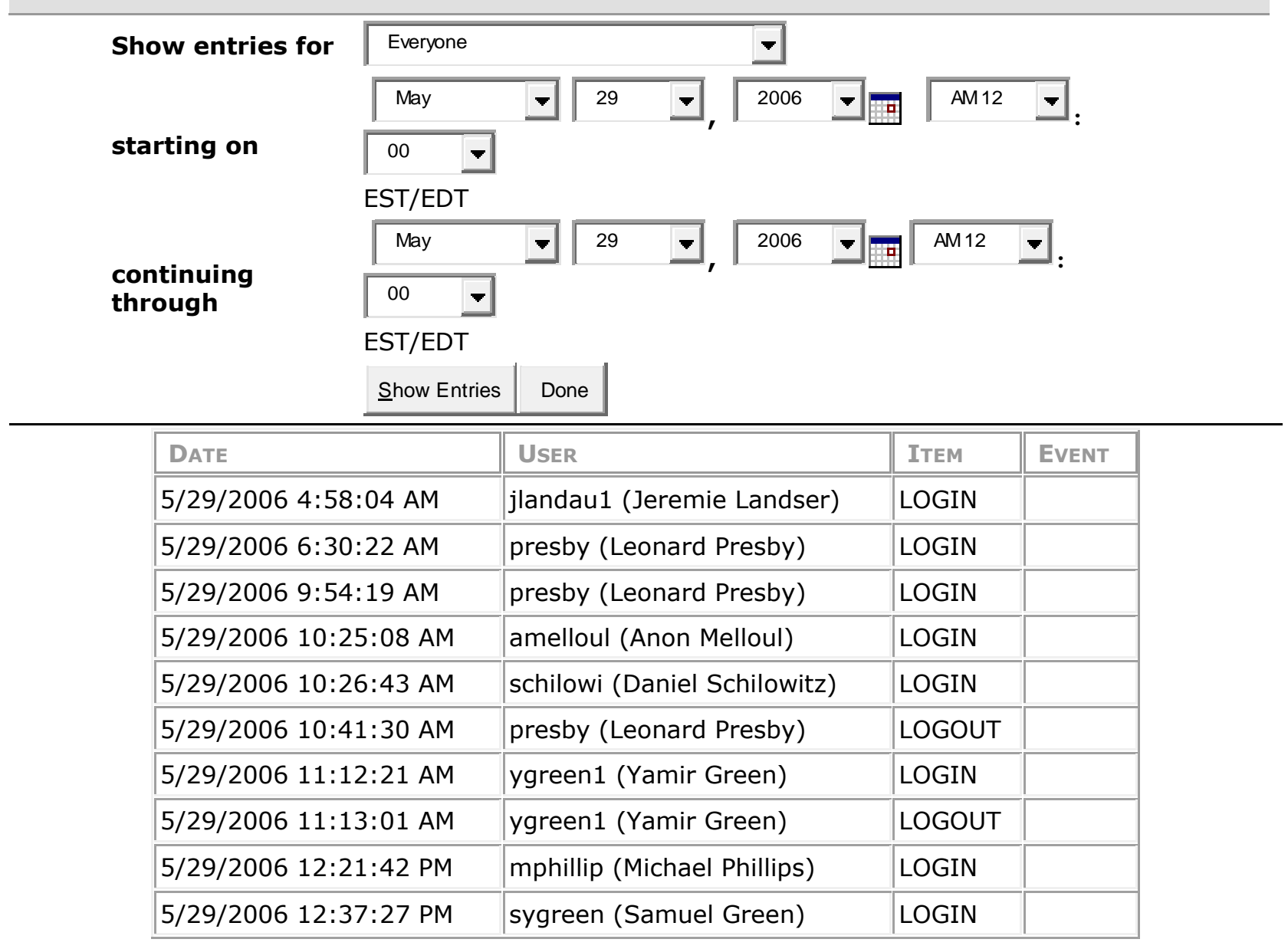
semester.

Another very useful feature is to see a summary report of how many times students have logged on for the 


\section{Login Report}

Management Info Systems - B

\begin{tabular}{|l||r||l||l|}
\multicolumn{5}{c|}{ Monday, May 29, 2006} \\
\hline USER & Logins & FIRST LogIN & LAST LogIN \\
\hline \hline Abed, Selha & 78 & $1 / 25 / 2006$ 2:29:15 PM & 5/27/2006 11:26:29 PM \\
\hline Birn, Laurie & 191 & $1 / 25 / 2006$ 11:22:24 AM & 5/29/2006 4:03:14 AM \\
\hline Celler, Farrah & 56 & $1 / 25 / 2006$ 11:27:55 AM & 5/24/2006 7:51:14 PM \\
\hline Dabah, Chana & 28 & 2/8/2006 10:40:51 AM & 5/21/2006 2:48:07 PM \\
\hline Deutsch, Courtney & 78 & $1 / 29 / 200610: 35: 51$ PM & 5/26/2006 5:01:37 PM \\
\hline
\end{tabular}

\section{CONCLUSION}

Angel's simple interface makes it easy for users to quickly begin using ANGEL. It allows the instructor to easily reuse previously developed content and to individualize instruction. The features exemplify the best of technology harnessed to enhance teaching and learning. ANGEL is robust with features like timed quizzes and the Who Dun It agent. It has Action Items let you create self-paced courses, conditionally release materials, and perform Features like the custom grade book and attendance manager to make tedious administrative tasks easier. The Learner Profile lets you view all student-related activities for any student in the course from one screen.

It allows instructors to efficiently manage instruction, communicate quickly, easily, and effectively, and develop the sophisticated learning experiences today's demanding educational climate requires. It helps them develop meaningful learning experiences. It helps students improve learning outcomes, provides sophistication and flexibility. It provides timesaving, pedagogically effective tools. ANGEL has features othe previous CMS didn't have like reporting functions, multiple drop boxes, discussion forums that are linked to the grade book. Overall, ANGEL is just more accommodating and useful. The ability to copy one course section to another, the ability to grade discussion forums, students' ability to use the equation editor and HTML editor are among some of the features which tend to be used. In order to help learners develop meaningful learning experiences, improve learning outcomes, provide timesaving, pedagogically effective tools, grab on to this ANGEL.

\section{LIMITATION OF THE STUDY AND FURTHER STUDIES}

One needs to consider numerous factors if one is considering changing from a current CMS. See, for example, an article on converting a Blackboard course. Some of the hazards and benefits of changing course management systems are discussed (Smart \& Meyer). Other articles discuss the several factors to consider in choosing a course-management system: comparison of a prospective software with the system being used; importance of a support staff to the system and decision on whether to buy or share in developing a system (Powell).

References available from author 
$\underline{\text { Notes }}$ 